\title{
Pin Nematode Slow Decline of Anthurium andraeanum, a New Disease Caused by the Pin Nematode Paratylenchus shenzhenensis
}

Ke Wang, Yu Li, Hui Xie, Wen-Jia Wu, and Chun-Ling Xu, Lab of Plant Nematology/Research Center of Nematodes of Plant Quarantine, Department of Plant Pathology, College of Agriculture, South China Agricultural University, Guangzhou, Guangdong 510642, China

\begin{abstract}
Wang, K., Li, Y., Xie, H., Wu, W.J., and Xu, C.L. 2016. Pin nematode slow decline of Anthurium andraeanum, a new disease caused by the pin nematode Paratylenchus shenzhenensis. Plant Dis. 100:940-945.

High population densities of the plant-parasitic nematode Paratylenchus shenzhenensis have been observed in association with stunted anthurium in Shenzhen, Guangdong Province, China. P. shenzhenensis is now recognized as a new pathogen that causes severe damage to anthurium. Commercial fields of anthurium infected by $P$. shenzhenensis present a patchy distribution of plants that are usually stunted and in decline and have yellowing leaves. Roots that are heavily infected by this nematode present brown, dark-brown, or black rot, and the entire root mass is often destroyed. In this study, a method of culturing $P$. shenzhenensis on carrot disks was established, and the effects of temperature and time on the reproduction rate $(\mathrm{Rr}=$ final number of nematodes/initial number of nematodes) of this nematode were

assessed. The optimum temperature for culturing $P$. shenzhenensis on carrot disks is $25^{\circ} \mathrm{C}$ and, after inoculation with 20 females and 10 males at $25^{\circ} \mathrm{C}$ for 10 weeks, $\mathrm{Rr}$ reached 3,834. At the optimum temperature, a suitable extension culture time or an increase in initial inoculum density will improve the reproductive efficiency of $P$. shenzhenensis. Koch's postulates were fulfilled by inoculating $P$. shenzhenensis on the roots of anthurium and demonstrating the pathogenicity of the nematode. Histological analyses showed that $P$. shenzhenensis feed endoparasitically on the roots of anthurium; whole nematode bodies were observed in the outermost epidermal cells and root hairs, and the cell walls and middle lamellae were partially dissolved because of nematode migration and feeding.
\end{abstract}

Anthurium (Anthurium andraeanum), a perennial evergreen herb belonging to the family Araceae, is a well-known flower species sold commercially worldwide (Atak and Çelik 2009). Anthurium is native to the wet western slopes of the Andes in southern Colombia and northern Ecuador (Criley 1989). Since the introduction of anthurium to Hawaii in 1889 , it has been widely cultivated, with large-scale production industries existing in a number of countries, including the Netherlands, the United States, Mauritius, and Jamaica (Alvarez et al. 2006). Anthurium was introduced to mainland China in the 1970 s and is now cultivated in many areas of China, with the major commercial production areas located in the provinces of Guangdong, Hainan, and Yunnan.

During the initial years of commercial production, anthurium was relatively disease free; however, diseases developed as cultivation expanded (Alvarez et al. 2006). Plant-parasitic nematodes are important pathogens that can cause serious damage to anthurium (Alvarez et al. 2006; Aragaki et al. 1984; Bala and Hosein 1996). For example, the burrowing nematode Radopholus similis can cause severe economic losses because it infects the roots and stems of anthurium and causes rot in the root tissues, which decreases plant growth (Sipes et al. 2001; Uchida et al. 2003). Complete damage of the belowground tissues of anthurium is common with severe infections by $R$. similis (Sipes et al. 2001). In addition, a number of other nematodes, such as Helicotylenchus dihystera, Meloidogyne incognita, Paratylenchus minutus, and Pratylenchus coffeae have been detected in the rhizosphere of anthurium (Bala and Hosein 1996).

Pin nematodes (Paratylenchus spp.) are root parasites of a large variety of plants, and certain species are pathogenic to their hosts (Brzeski 1995; Siddiqi 2000). Paratylenchus microdorus, P. neoamblycephalus, $P$. bukowinensis, $P$. projectus, and $P$. hamatus infect the roots of lettuce, myrobalan plum, carrot, tobacco, and rose,

Corresponding author: H. Xie; E-mail: xiehui@scau.edu.cn

Accepted for publication 25 November 2015.

http://dx.doi.org/10.1094/PDIS-07-15-0777-RE

(C) 2016 The American Phytopathological Society respectively, and can cause poor growth, decreased yields, and low quality (Andrássy 1985; Braun and Lownsbery 1975; Brzeski 1976 , 1995; Loof 1975; MacDonald 1976). Other reports have shown that certain species of Paratylenchus may reach large densities around the roots without causing obvious damage to their hosts. For example, $P$. projectus reproduces well on Ladino clover without a decrease in plant yield (Loof 1975). Linford et al. (1949) reported that large population densities of $P$. minutus were detected on the rhizosphere of pineapple that showed normal growth and lacked visible pathological changes in the plant cells.

During a survey of plant-parasitic nematodes associated with ornamental plants in China conducted by our group in 2011, a new species of Paratylenchus named P. shenzhenensis was discovered in association with anthurium, with high densities in Shenzhen, Guangdong Province (Wang et al. 2013). The objectives of this study were to establish a method of culturing $P$. shenzhenensis on carrot disks and provide a description of this new pin nematode slow decline disease of anthurium caused by $P$. shenzhenensis.

\section{Materials and Methods}

Nematode collection. In total, 42 samples were collected from two commercial anthurium fields in Shenzhen, Guangdong Province, China from May to June 2011. Each sample consisted of at least five sampling points from patches of poor growth. Samples were placed in plastic bags and stored at 16 to $18^{\circ} \mathrm{C}$. Nematodes in the roots and soil samples were extracted from $100-\mathrm{cm}^{3}$ subsamples using a modified Baermann funnel method (Hooper et al. 2005).

Nematode culturing and experiments. Carrot (Daucus carota) disks were prepared according to the methods of Moody et al (1973) and Kaplan and Davis (1990). Carrot roots were surface sterilized with $95 \%$ ethanol. The external tissues were removed with a sterile knife, and then the carrot was cut into disks (about $6 \mathrm{~mm}$ thick). Each disk was placed in a 6-cm-diameter petri dish and maintained at $25^{\circ} \mathrm{C}$ for 3 weeks for later use. Nematode inoculum was surface sterilized with $0.3 \%$ streptomycin sulfate for $8 \mathrm{~h}$ (Stoffelen et al. 1999).

Using the carrot disk method, two experiments were conducted to determine the reproduction potential of one or more $P$. shenzhenensis females. In the first experiment, a single $P$. shenzhenensis female was 
handpicked, surface sterilized with streptomycin sulfate, and placed onto a carrot disk in a petri dish. In the second experiment, 60 females were handpicked, sterilized, and then added to one carrot disk in a petri dish. These petri dishes were sealed with parafilm and incubated at $25^{\circ} \mathrm{C}$ in the dark. The two experiments were terminated to assess whether $P$. shenzhenensis reproduction had occurred after 15 weeks, and the success rates of reproduction (the number of carrot disks in which reproduction occurred/the initial number of carrot disks inoculated with nematodes) were determined. A maceration technique (Hooper et al. 2005) was used to collect nematodes: the carrot disks were placed in about $100 \mathrm{ml}$ of water and macerated in a blender, and the suspension was then passed through 0.250 - and $0.150-\mathrm{mm}$-pore sieves to separate the nematodes from the carrot tissues. The nematodes were washed through the sieves into a beaker, and the carrot tissues collected on the sieves were discarded. Then, the nematode suspension in the beaker was left to settle for at least $4 \mathrm{~h}$ and the supernatant was removed with a pipette. The remaining nematode suspension was observed under a stereomicroscope to assess whether $P$. shenzhenensis reproduction had occurred, and the success rate of reproduction was then determined. There were 10 replicates for each experiment, and each experiment was conducted twice.

To evaluate the effect of temperature on the reproduction of $P$. shenzhenensis, the carrot disk method was also used. Twenty females and 10 males were handpicked and added to a carrot disk and the disks were incubated at 18,25 , and $30^{\circ} \mathrm{C}$ in the dark. The number of nematodes and reproduction rate $(\mathrm{Rr}=$ final number of nematodes/initial number of nematodes) on each carrot disk were determined at 10 weeks after inoculation. The effect of time on the reproduction of $P$. shenzhenensis was investigated by adding 40 females and 20 males to each carrot disk and incubating the disks at $25^{\circ} \mathrm{C}$ in the dark. The number of nematodes and $\mathrm{Rr}$ on each carrot disk were determined at 5,10 , and 15 weeks after inoculation. The culture characteristics of the nematodes on the carrot disks with 40 females and 20 males were observed after 15 weeks of inoculation at $25^{\circ} \mathrm{C}$. The maceration technique, as described above, was also used to collected nematodes. The nematode suspension was collected in a beaker and left to settle for at least $4 \mathrm{~h}$, the supernatant water was removed, and the volume was adjusted to $100 \mathrm{ml}$. Nematodes in three $200-\mu l$ suspensions were pipetted into 6-cm-diameter petri dishes and counted under a stereomicroscope. The average number of nematodes in the 200- $\mu$ l suspensions was calculated, and the total nematode number was determined. There were five replicates for each experiment, and each experiment was conducted twice.

Pathogenicity tests. Anthurium seedlings were purchased from the Flowers and Plants Research Center (Guangzhou, Guangdong, China) and evaluated as being free from plant-parasitic nematodes using the method described by Zhang et al. (2012). The roots of each anthurium seedling were gently washed free of soil with sterile water. The soil and water were collected in a beaker and allowed to settle for $4 \mathrm{~h}$; then, the supernatant liquid was carefully removed, leaving the

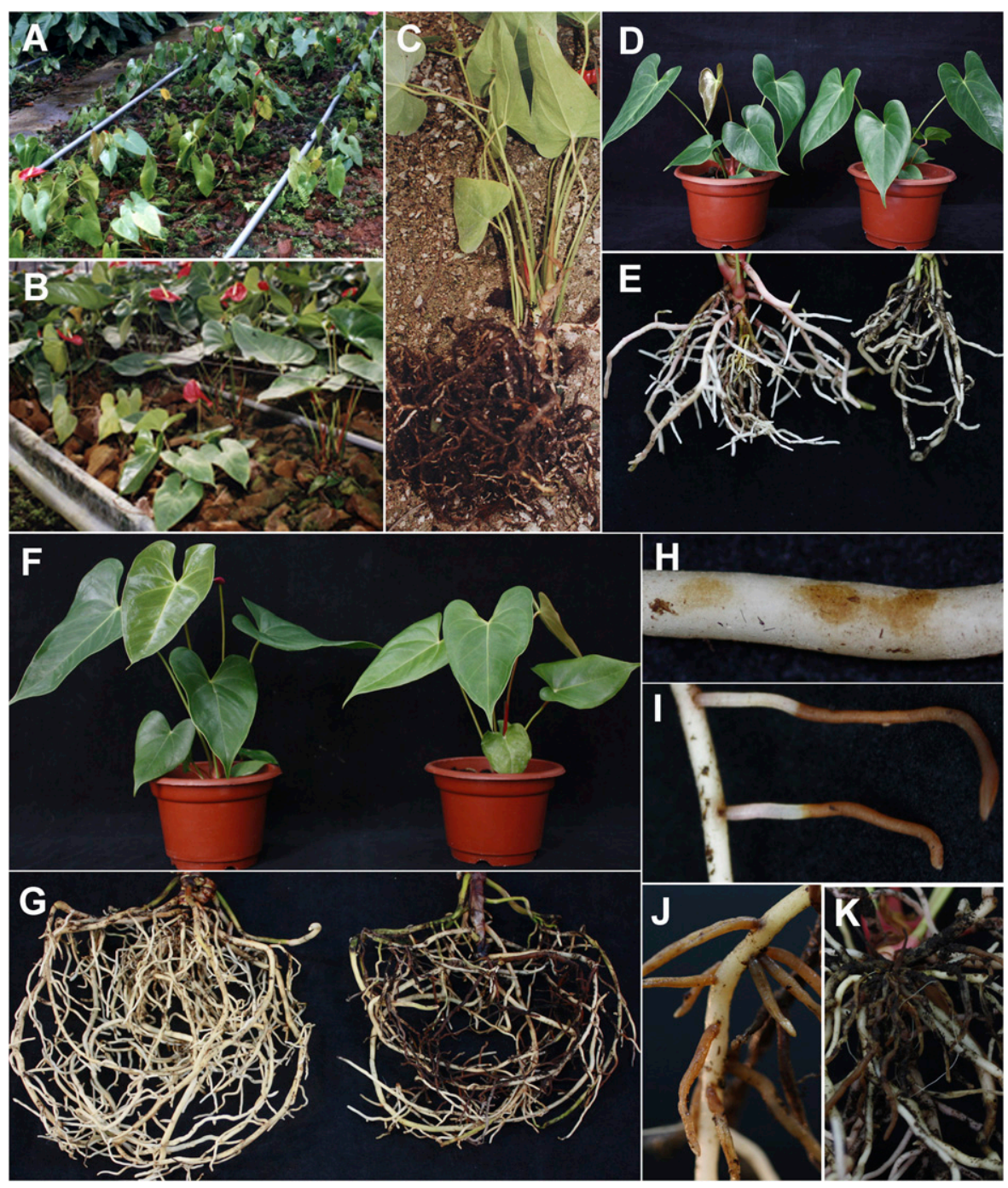

Fig. 1. Anthurium andraeanum infected by the pin nematode Paratylenchus shenzhenensis. $\mathbf{A}$ and $\mathbf{B}$, Patches of diseased plants; $\mathbf{C}$, rot root of anthurium; $\mathbf{D}$ and $\mathbf{E}$, shoot and roots of an infected anthurium (right) compared with that of an uninoculated plant (left) 4 months after inoculation with $P$. shenzhenensis; $\mathbf{F}$ and $\mathbf{G}$, shoot and roots of an infected anthurium (right) compared with that of an uninoculated plant (left) 8 months after inoculation with P. shenzhenensis; $\mathbf{H}$, initial symptoms on the root; I, enlarged lesions on the roots; and $\mathrm{J}$ and $\mathrm{K}$, severely diseased roots. 
sediment in the bottom. The modified Baermann funnel was used to extract the nematodes in the sediment and microscope inspection was employed. If there were no plant-parasitic nematodes in the sediment, the corresponding seedling was chosen and grown in a 1.8-liter pot filled with 1.5 liters of sterilized soil medium for 30 days. The pathogenicity studies were performed with the population of $P$. shenzhenensis originally isolated from infected anthurium in the commercial fields in Shenzhen and cultured on carrot disks at $25^{\circ} \mathrm{C}$. The nematodes were extracted from the disks using the modified Baermann funnel method and adjusted to a suspension with 1,500 nematodes $/ \mathrm{ml}$. Anthurium seedlings with the same growth status were selected, and six small holes $(5 \mathrm{~cm}$ deep) were made near the roots using a glass rod. A 2-ml suspension containing 3,000 nematodes was then pipetted into the holes. For the noninoculated controls, $2 \mathrm{ml}$ of sterile water was pipetted into the holes. The holes were subsequently closed with soil medium. At 4 and 8 months after inoculation, plant growth and nematode reproduction were measured. The overall height of the plants and the fresh weight of the aerial parts and roots were determined and symptoms of the infection were photographed. Nematodes in roots were extracted using the maceration technique described above. Then, the number of nematodes in the suspension was determined. Nematodes in the soil medium were extracted using the modified Baermann funnel method. Total number of nematodes was calculated as the sum of nematodes isolated from roots and soil, and then the $\mathrm{Rr}$ was determined. There were five replications for each inoculation period ( 4 and 8 months), and the experiment was performed twice.

Histopathology. At 8 months after inoculation, a procedure for staining nematode-infected roots was performed according to Braun and Lownsbery (1975) and Byrd et al. (1983). The roots were gently removed from pots, and approximately $2 \mathrm{~g}$ of roots from each plant were immersed in $90^{\circ} \mathrm{C}$ water in a beaker for $1 \mathrm{~min}$, then dipped in cold water, resulting in the removal of most of the soil from the roots. The roots were then immersed in boiling acid fuchsin for $15 \mathrm{~min}$. After cooling to room temperature, the roots were transferred to a $0.1-\mathrm{mm}$ sieve to wash off excess stain in running water. Then, the roots were cut into $1-\mathrm{cm}$ sections and examined under a microscope. Paraffin sections were produced according to Sasanelli et al. (2013). Approximately $2 \mathrm{~g}$ of infected roots from each plant were gently washed free from soil, cut into 4- to 5-mm-long segments, fixed in formaldehydeacetic acid-ethanol solution for $48 \mathrm{~h}$, dehydrated in a tertiary butyl alcohol series $(40,70,85,90$, and $100 \%)$, embedded in paraffin wax with a melting point of $58^{\circ} \mathrm{C}$, and sectioned $(6 \mu \mathrm{m}$ thick) with a rotary microtome. The sections were stained with safranin and fast-green, mounted on glass slides, examined, and photographed using a Nikon Eclipse 90i microscope (Nikon, Tokyo).

Statistical analysis. Data were analyzed using SPSS software (ver. 13.0; SPSS Inc., Chicago). Preliminary analyses showed that there was no significant difference $(P>0.05)$ between the data from two runs of each experiment using independent-sample $t$ tests, and that allowed data from two runs to be combined for analyses. In the culture study, data on $P$. shenzhenensis cultured on carrot disks under different conditions were subjected to a one-way analysis of variance, and differences were tested using Duncan's multiple range test at the 5\% significance level. In the pathogenicity study, data were tested for differences using independent-sample $t$ tests at a 5\% level.

\section{Results}

Field symptoms. $P$. shenzhenensis was detected in 29 of 42 samples collected from the two commercial fields, and high populations (approximately 7,600 nematodes per $100 \mathrm{~cm}^{3}$ of sample) were observed. Commercial fields of anthurium infected by $P$. shenzhenensis showed a patchy distribution of plants that were generally stunted and in decline, with yellowing leaves. Anthurium roots heavily infected with nematodes presented brown, dark-brown, or black rot, and the entire root mass was destroyed (Fig. 1A to C).

Reproduction potential of one or more $P$. shenzhenensis females. At 15 weeks after inoculation, reproduction was observed in the experiments with 1 female and with 60 females. Of the initial 10 carrot disks inoculated with a single female, reproduction occurred on 3 carrot disks in the first run of the experiment and on 2 in the second run, and the success rate of reproduction was 30 and $20 \%$ in the two runs, respectively. Of the initial 10 carrot disks inoculated with 60 females, reproduction occurred on 4 disks in both runs of the experiment, and the success rate of reproduction was $40 \%$. Numerous adults, juveniles, and eggs were extracted from the carrot disks and observed under a stereomicroscope.

Effects of temperature and time on the $R r$ of pin nematodes. At 10 weeks after inoculation with 20 females and 10 males, reproduction occurred on all the carrot disks, and the Rr reached 192, 3,834, and 3,895 at 18,25 , and $30^{\circ} \mathrm{C}$, respectively (Table 1 ). When cultured at 25 and $30^{\circ} \mathrm{C}$, the $\mathrm{Rr}$ were all significantly higher $(P<0.05)$ relative to culturing at $18^{\circ} \mathrm{C}$ but a significant difference was not observed between the cultures at 25 and $30^{\circ} \mathrm{C}(P>0.05)$. After inoculation with 40 females and 20 males at $25^{\circ} \mathrm{C}$ for 5,10 , and 15 weeks, reproduction occurred on all the carrot disks, and the $\mathrm{Rr}$ reached 220, 4,236, and 9,008, respectively. Significant differences $(P<0.05)$ were observed among the three different culture times (Table 2). In addition, when incubated at $25^{\circ} \mathrm{C}$ for 10 weeks, the nematode populations reached 115,028 and 254,168 after inoculation with 30 nematodes (20 females and 10 males) and 60 nematodes (40 females and 20 males), respectively, and a significant difference was observed $(P<0.05)$ between the two initial inoculum densities. The observed culture characteristics showed that, at 15 weeks after inoculation with 40 females and 20 males at $25^{\circ} \mathrm{C}$, the carrot disks presented obvious infection symptoms and turned a brown or dark-brown color. Nematode swarms could be observed on the bottoms of the petri dishes.

Table 1. Effect of temperature $(\mathrm{Tm})$ on the reproduction of Paratylenchus shenzhenensis on carrot callus 10 weeks after inoculation with 20 females and 10 males ${ }^{\mathrm{x}}$

\begin{tabular}{|c|c|c|c|c|c|c|}
\hline $\operatorname{Tm}\left({ }^{\circ} \mathrm{C}\right)$ & Females & Males & Juveniles & Eggs & $P f^{y}$ & $\mathrm{Rr}=P f / P i^{\mathrm{z}}$ \\
\hline 18 & $1,090 \pm 81.4 \mathrm{~b}$ & $365 \pm 14.1 \mathrm{c}$ & $911 \pm 60.6 \mathrm{c}$ & $3,404 \pm 219.8 \mathrm{c}$ & $5,770 \pm 274.3 \mathrm{~b}$ & $192 \pm 9.1 \mathrm{~b}$ \\
\hline 25 & $48,169 \pm 852.4 \mathrm{a}$ & $2,162 \pm 197.7 b$ & $11,637 \pm 778.0 \mathrm{~b}$ & $53,060 \pm 635.4 \mathrm{a}$ & $11,5028 \pm 1,340.9 \mathrm{a}$ & $3,834 \pm 44.7 \mathrm{a}$ \\
\hline 30 & $49,163 \pm 1,112.5 \mathrm{a}$ & $4,113 \pm 181.1 \mathrm{a}$ & $20,550 \pm 697.7 \mathrm{a}$ & $43,012 \pm 862.9 \mathrm{~b}$ & $11,6838 \pm 841.1 \mathrm{a}$ & $3,895 \pm 28.0 \mathrm{a}$ \\
\hline
\end{tabular}

${ }^{x}$ Different letters in columns indicate significant differences $(P<0.05)$ according to Duncan's multiple range test. Each number is the average of two trials, each with five replicates. Values represent the mean \pm standard error.

y $P f=$ final number of nematodes, including eggs and vermiform stages.

${ }^{\mathrm{z}}$ Reproduction rates of nematodes $(\mathrm{Rr})=P f /$ initial number of nematodes $(P i)$.

Table 2. Reproduction of Paratylenchus shenzhenensis on carrot callus 5, 10, and 15 weeks after inoculation with 40 females and 20 males, incubated at $25^{\circ} \mathrm{C}^{\times}$

\begin{tabular}{|c|c|c|c|c|c|c|}
\hline Time (weeks) & Females & Males & Juveniles & Eggs & $P f^{\mathbf{y}}$ & $\mathrm{Rr}=P f / P i^{\mathrm{z}}$ \\
\hline 5 & $1,425 \pm 52.4 \mathrm{c}$ & $888 \pm 35.1 \mathrm{c}$ & $4,204 \pm 155.1 \mathrm{c}$ & $6,680 \pm 116.4 c$ & $13,197 \pm 271.2 \mathrm{c}$ & $220 \pm 4.5 \mathrm{c}$ \\
\hline 10 & $65,717 \pm 1,936.7 \mathrm{~b}$ & $11,650 \pm 680.3 b$ & $70,566 \pm 1,476.0 \mathrm{~b}$ & $10,6235 \pm 1,643.0 \mathrm{~b}$ & $25,4168 \pm 3,137.4 b$ & $4,236 \pm 52.3 b$ \\
\hline 15 & $14,2235 \pm 3,518.7 \mathrm{a}$ & $22,568 \pm 902.8 \mathrm{a}$ & $24,0932 \pm 7,764.5 \mathrm{a}$ & $13,4732 \pm 2,326.8 \mathrm{a}$ & $54,0467 \pm 5,885.4 \mathrm{a}$ & $9,008 \pm 98.1 \mathrm{a}$ \\
\hline
\end{tabular}

${ }^{\mathrm{x}}$ Different letters in columns indicate significant differences $(P<0.05)$ according to Duncan's multiple range test. Each number is the average of two trials, each with five replicates. Values represent the mean \pm standard error.

y $P f=$ final number of nematodes, including eggs and vermiform stages.

${ }^{\mathrm{z}}$ Reproduction rates of nematodes $(\mathrm{Rr})=P f /$ initial number of nematodes $(P i)$. 
Pathogenicity and histology. Four months after nematode inoculation, the aerial parts of anthurium did not show obvious disease symptoms, whereas the roots were reduced and slightly rotted compared with those of uninoculated plants (Fig. 1D and E). The average number of $P$. shenzhenensis nematodes extracted from each

Table 3. Population density of Paratylenchus shenzhenensis recovered from Anthurium andraeanum 4 months after inoculation and the effects of $P$. shenzhenensis on plant growth ${ }^{\mathrm{y}}$

\begin{tabular}{lcccccc}
\hline \multicolumn{2}{c}{ Population } & & & \multicolumn{2}{c}{ Fresh weight $(\mathbf{g})$} \\
\cline { 1 - 2 } \cline { 5 - 7 } Initial & Final & & Rr $^{\mathbf{z}}$ & Height $(\mathbf{c m})$ & Shoot & Root \\
\hline 3,000 & $39,901 \pm 1,419$ & $13.3 \pm 0.5$ & $20.1 \pm 0.3$ & $16.0 \pm 0.3$ & $14.6 \pm 0.3$ \\
0 & 0 & $\ldots$ & $20.9 \pm 0.4$ & $17.5 \pm 0.4$ & $17.8 \pm 0.5$ \\
$t$ & $\ldots$ & $\ldots$ & -1.911 & -4.266 & -7.952 \\
$P$ & $\ldots$ & $\ldots$ & 0.072 & 0.000 & 0.000 \\
\hline
\end{tabular}

${ }^{\mathrm{y}}$ Each number is the average of two trials, each with five replicates. Values represent the mean \pm standard error.

${ }^{\mathrm{z}}$ Reproduction rates of nematodes $(\mathrm{Rr})=$ final number of nematodes/initial number of nematodes.

Table 4. Population density of Paratylenchus shenzhenensis recovered from Anthurium andraeanum 8 months after inoculation and the effects of $P$. shenzhenensis on plant growth ${ }^{\mathrm{y}}$

\begin{tabular}{|c|c|c|c|c|c|}
\hline \multicolumn{2}{|r|}{ Population } & \multirow[b]{2}{*}{$\mathbf{R r}^{\mathbf{z}}$} & \multirow[b]{2}{*}{ Height (cm) } & \multicolumn{2}{|c|}{ Fresh weight (g) } \\
\hline Initial & Final & & & Shoot & Root \\
\hline 3,000 & $12,3176 \pm 3,611$ & $41.1 \pm 1.2$ & $26.0 \pm 1.2$ & $26.5 \pm 1.1$ & $32.8 \pm 1.9$ \\
\hline 0 & 0 & $\ldots$ & $37.7 \pm 1.8$ & $42.5 \pm 1.5$ & $47.6 \pm 1.6$ \\
\hline$t$ & $\ldots$ & $\ldots$ & -7.785 & -11.981 & -9.770 \\
\hline$P$ & $\ldots$ & $\ldots$ & 0.000 & 0.000 & 0.000 \\
\hline
\end{tabular}

${ }^{\mathrm{y}}$ Each number is the average of two trials, each with five replicates. Values represent the mean \pm standard error.

${ }^{\mathrm{z}}$ Reproduction rates of nematodes $(\mathrm{Rr})=$ final number of nematodes/initial number of nematodes. inoculated plant was 39,901 $\pm 1,419$. Significant differences in plant height were not observed between the uninoculated controls and the inoculated plants $(P>0.05)$ but there were significant decreases $(P<0.05)$ in the fresh weight (top and root) of the inoculated plants (Table 3).

Eight months after inoculation, obvious disease symptoms were observed, including reduced plant growth and height, lost leaf luster, marked reductions in roots, and serious root rot (Fig. $1 \mathrm{~F}$ and $\mathrm{G}$ ). The average number of $P$. shenzhenensis nematodes extracted from each of the inoculated plants was $123,176 \pm 3,611$. The overall height of the plants and the fresh weight of the shoots and roots were significantly decreased compared with that of the uninoculated plants $(P<0.05$; Table 4$)$. The root symptoms were initially small, yellow-brown spots (Fig. 1H). The spots enlarged gradually, causing large sections of the root to turn a yellow-brown color (Fig. 1I). Over time, all of the sections of one root became brown, dark brown, or black and the root was destroyed and easily breakable (Fig. 1J and $\mathrm{K})$. Staining showed that a large quantity of $P$. shenzhenensis nematodes, including females, males, and juveniles, was present in the root epidermal cells and root hairs (Fig. 2A to F). The histological evaluation of the cross sections of infected roots also indicated that nematodes and eggs were present in the outermost layer of epidermal cells, and the cell walls and middle lamellae were partially dissolved because of nematode migration and feeding; however, nematodes were not detected in the other cell layers (Fig. 2G to J).

\section{Discussion}

A number of fungi, such as Pythium splendens, Phytophthora cinnamomi, and Calonectria crotalariae, are pathogenic to anthurium roots and cause the roots to rot (Aragaki et al. 1984). The role that plant-parasitic nematodes, particularly $R$. similis, play in anthurium root damage has attracted wide public concern (Aragaki et al. 1984; Uchida et al. 2003). Although Paratylenchus minutus has been found in association with anthurium (Bala and Hosein 1996), Paratylenchus spp. have not been previously shown to cause damage to

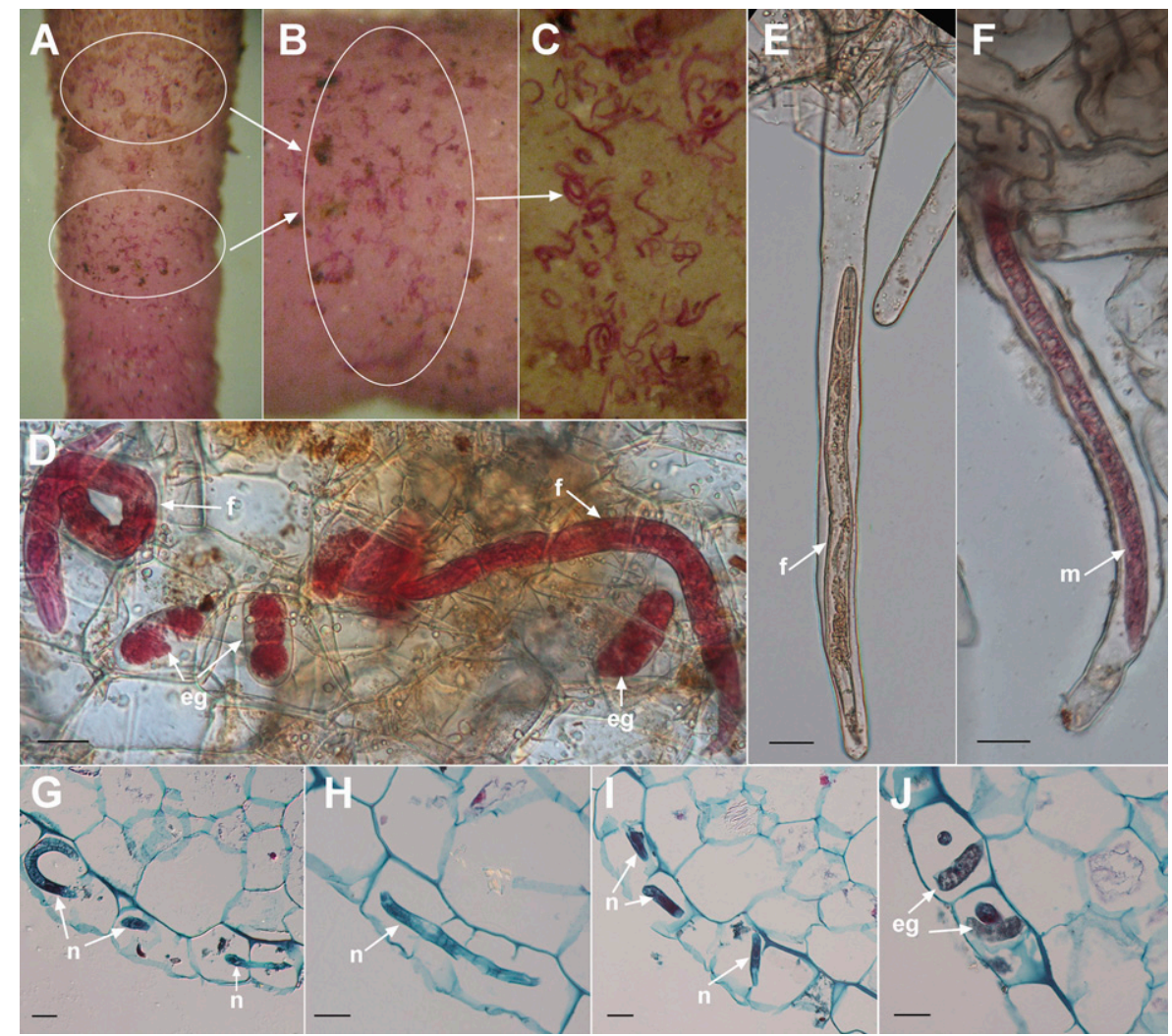

Fig. 2. Paratylenchus shenzhenensis (mixed-stage vermiforms and eggs) in Anthurium andraeanum root tissues. $\mathbf{A}$ to $\mathbf{C}$, Large population densities of vermiform individuals and eggs in roots; D, Females (f) and eggs (eg) in the epidermal cells; $\mathbf{E}$ and F, females ( $f$ ) and males ( $\mathrm{m}$ ) in the root hairs; and $\mathbf{G}$ to $\mathbf{J}$, cross section of roots infected with $P$. shenzhenensis showing vermiform nematodes $(n)$ and eggs $(e g)$ in damaged epidermal cells. Scale bars $(D$ to $J)=20 \mu m$. 
anthurium. In this study, we demonstrated that anthurium slow decline caused by $P$. shenzhenensis is a new disease that fulfills Koch's postulate. The pathogenicity of $P$. shenzhenensis to anthurium was confirmed in laboratory studies, and a microscopic examination of the roots of anthurium inoculated with the nematode confirmed the presence of this nematode. The parasitic habits of many Paratylenchus spp. qualify them as ectoparasites. For example, $P$. neoamblycephalus, $P$. bukowinensis, $P$. minutus, $P$. latescens, and $P$. peraticus usually adhere to the root surface, with their heads or stylets penetrating into the root tissues, and these nematodes usually do not exhibit body penetration of the root tissues (Braun and Lownsbery 1975; Brzeski 1976; Linford et al. 1949; Troccoli et al. 2002). P. projectus is usually found with its body outside the root although, in certain cases, the nematode may penetrate through existing openings or cracks in the root epidermis and feed endoparasitically (Loof 1975). Cid del Prado Vera and Maggenti (1988) reported that $P$. hamicaudatus attaches to the stele or vascular cylinder, and was only detected in the secondary roots under the cortex, with no portion of the body exposed outside of the cortex. In this study, we found that $P$. shenzhenensis fed endoparasitically on the roots of anthurium, and the entire body of the nematode was observed in the outermost epidermal cells or root hairs. The females of $P$. shenzhenensis laid eggs and completed their life cycle in the epidermal cells. The nematodes were not detected in other cell layers.

Culturing plant-parasitic nematodes is important because it enables pathogenicity tests and biological studies. The culture methods for plant-parasitic nematodes have long been explored, and several methods have been reported over the years (Kagoda et al. 2010; Krusberg 1961; Reise et al. 1987). However, only a small number of plant-parasitic nematodes have been cultured, and the culture methods are quite different. For example, Ditylenchus destructor, Aphelenchoides besseyi, and Bursaphelenchus xylophilus can be cultured on certain fungi (Liu and Zheng 2006; Wang et al. 2008; Zhu et al. 2012) and A. ritzemabosi and D. dipsaci can reproduce on alfalfa tissue (Krusberg 1961), whereas $P$. projectus failed to reproduce on alfalfa tissue (Townshend 1974). Carrot tissue can be used to culture A. besseyi, A. ritzemabosi, $R$. similis, and certain species of Pratylenchus, whereas it cannot be used to culture H. multicinctus (Kagoda et al. 2010; Pei et al. 2010; Peng et al. 2015; Stoffelen et al. 1999). Townshend (1974) reported that, at 5 weeks after inoculation on white clover callus, numerous $P$. projectus individuals were observed near the callus, although the nematode failed to multiply on alfalfa callus. Braun and Lownsbery (1975) reported that $P$. neoamblycephalus did not reproduce on myrobalan plum callus. $P$. projectus was previously considered the only species of Paratylenchus that could be successfully cultured; however, the inoculation method was laborious and time consuming because of the callus preparation. In addition, the callus can easily become contaminated with microorganisms after inoculation with the nematodes, which may reduce reproduction in the nematodes.

This study is the first to demonstrate that the carrot disk method is suitable for culturing $P$. shenzhenensis. Use of this method led to rapid reproduction, thus requiring less labor and time. Reproduction occurred using 1 and 60 females of $P$. shenzhenensis but both experiments had a low rate of reproductive success. However, a reproductive success rate of $100 \%$ was observed when females and males were inoculated simultaneously. Although the density of $P$. shenzhenensis males is much less than that of females in the field, females have spermatheca filled with sperm. Therefore, the results presented here indicate that $P$. shenzhenensis may primarily reproduce by sexual reproduction. In this study, $P$. shenzhenensis quickly reproduced on carrot disks at 25 and $30^{\circ} \mathrm{C}$ but the carrot disks inoculated with nematodes rotted easily at $30^{\circ} \mathrm{C}$. Thus, the optimum temperature for culturing $P$. shenzhenensis on carrot disks is $25^{\circ} \mathrm{C}$. The results of this study also indicate that the culture temperature and length and initial inoculum density all affect the $\operatorname{Rr}$ of $P$. shenzhenensis on carrot disks. At $25^{\circ} \mathrm{C}$, a suitable extension culture time or an increase in initial inoculum density will improve the reproductive efficiency of $P$. shenzhenensis.
Anthurium plants prefer warm surroundings, and the optimum temperature for growth and development is 22 to $32^{\circ} \mathrm{C}$ (Huang et al. 2006). Thus, we conclude that the outbreak of anthurium slow decline disease caused by $P$. shenzhenensis may have been promoted by the suitable growth temperature range in the study area. This study also suggests that anthurium root rot caused by $P$. shenzhenensis develops slowly. At the early stages of infection, the disease severity was low and obvious symptoms were not observed in the aerial parts. Over time, large population densities of nematodes multiplied on the roots, gradually destroying the root system and causing the plant to decline. Thus, this hidden and long-term hazard to anthurium should be further investigated. As a quarantine pest, $R$. similis is an important plant-parasitic nematode that causes severe damage to anthurium. In this study, we discovered that the root rot disease symptoms caused by $P$. shenzhenensis are similar to those caused by $R$. similis, which suggests that the accurate identification of nematodes is crucial for applying appropriate control measures.

\section{Acknowledgments}

This work was supported by the National Foundation of Natural Science of China (numbers 30671366 and 31071665 ).

\section{Literature Cited}

Alvarez, A. M., Toves, P. J., and Vowell, T. S. 2006. Bacterial blight of anthuriums: Hawaii's experience with a global disease. Online publication. APS Features. doi:10.1094/APSnetFeature-2006-0206

Andrássy, I. 1985. Paratylenchus microdorus. CIH Descriptions of Plant-Parasitic Nematodes, Set 8, No. 107. Commonwealth Agricultural Bureau, Farnham Royal, UK.

Aragaki, M., Apt, W. J., Kunimoto, R. K., Ko, W. H., and Uchida, J. Y. 1984 Nature and control of anthurium decline. Plant Dis. 68:509-511.

Atak, C.., and Çelik, Ö. 2009. Micropropagation of Anthurium andraeanum from leaf explants. Pak. J. Bot. 41:1155-1161.

Bala, G., and Hosein, F. 1996. Plant-parasitic nematodes associated with anthuriums and other tropical ornamentals. Nematropica 26:9-14.

Braun, A. L., and Lownsbery, B. F. 1975. The pin nematode, Paratylenchus neoamblycephalus, on myrobalan plum and other hosts. J. Nematol. 7:336-343.

Brzeski, M. W. 1976. Paratylenchus bukowinensis. CIH Descriptions of PlantParasitic Nematodes, Set 6, No. 79. Commonwealth Agricultural Bureau, Farnham Royal, UK.

Brzeski, M. W. 1995. Paratylenchinae: Morphology of some known species and descriptions of Gracilacus bilineata sp. n. and G. vera sp. n. (Nematoda: Tylenchulidae). Nematologica 41:535-565.

Byrd, D. W., Kirkpatrick, T., and Barker, K. R. 1983. An improved technique for clearing and staining plant tissues for detection of nematodes. J. Nematol. 15: 142-143.

Cid del Prado Vera, I., and Maggenti, A. R. 1988. Description of Gracilacus harnicaudata sp. n. (Nemata: Criconematidae) with biological and histopathological observations. Rev. Nematol. 11:29-33.

Criley, R. A. 1989. Culture and cultivar selection for anthurium in Hawaii. Acta Hortic. 246:227-236

Hooper, D. J., Hallmann, J., and Subbotin, S. A. 2005. Methods for extraction, processing and detection of plant and soil nematodes. Pages 53-86 in: Plant Parasitic Nematodes in Subtropical and Tropical Agriculture, 2nd ed., M. Luc, R. A. Sikora, and J. Bridge, eds. CABI Publishing, Wallingford, UK.

Huang, P. P., Zhang, Z. Y., Liang, J. P., Chen, B. Q., and Su, Z. S. 2006 Techniques for rapid propagation and culture-management of Anthurium andraeanum. Guangxi Agric. Sci. 37:113-116.

Kagoda, F., Coyne, D. L., Mbiru, E., Derera, J., and Tongoona, P. 2010 Monoxenic culture of Pratylenchus zeae on carrot discs. Nematol. Mediterr. 38:107-108.

Kaplan, D. T., and Davis, E. L. 1990. Improved nematode extraction from carrot disk culture. J. Nematol. 22:399-406.

Krusberg, L. R. 1961. Studies on the culturing and parasitism of plant-parasitic nematodes, in particular Ditylenchus Dipsaci and Aphelenchoides Ritzeiwabosi on alfalfa tissues. Nematologica 6:181-200.

Linford, M. B., Oliveira, J. M., and Ishii, M. 1949. Paratylenchus minutus n. sp., a nematode parasitic on roots. Pac. Sci. 3:111-119.

Liu, B., and Zheng, J. W. 2006. Monoxenic culture of Ditylenchus destructor on Botrytis cinerea. Acta Agric. Zhejiangensis 18:445-447.

Loof, P. A. A. 1975. Paratylenchus projectus. CIH Descriptions of Plant-Parasitic Nematodes, Set 5, No. 71. Commonwealth Agricultural Bureau, Farnham Royal, UK.

MacDonald, D. H. 1976. Effects of Paratylenchus hamatus on productivity of greenhouse roses. J. Nematol. 8:294.

Moody, E. H., Lownsbery, B. F., and Ahmed, J. M. 1973. Culture of the root-lesion nematode Pratylenchus vulnus on carrot disks. J. Nematol. 5:225-226. 
Pei,Y., Luo, A. L., Xie, H., Yang, Z. F., Cheng, X., and Xu, C. L. 2010. Reproductive fitness of 15 Aphelenchoides besseyi populations from China. J. Northwest A \& F Univ. 38:165-170.

Peng, X. F., Chen, D. Q., Wang, D. W., Wang, K., Wu, W. J., Xu, C. L., and Xie, H. 2015. Culture conditions and reproductive characteristics of Aphelenchoides ritzemabosi on callus. J. Huazhong Agric. Univ. 34:1-4.

Reise, R. W., Huettel, R. N., and Sayre, R. M. 1987. Carrot callus tissue for culture of endoparasitic nematodes. J. Nematol. 19:387-389.

Sasanelli, N., Vovlas, N., Trisciuzzi, N., Cantalapiedra-Navarrete, C., PalomaresRius, J. E., and Castillo, P. 2013. Pathogenicity and host-parasite relationships of Heterodera cruciferae in cabbage. Plant Dis. 97:333-338.

Siddiqi, M. R. 2000. Tylenchida Parasites of Plants and Insects, 2nd ed. CABI Publishing, Wallingford, UK.

Sipes, B. S., Schmitt, D. P., and Nelson, S. C. 2001. Burrowing nematode, a major pest in the tropics. Univ. Hawaii CTAHR Plant Dis. Publ. PD-21.

Stoffelen, R., Jimenez, M. I., Dierckxsens, C., Tam, V. T. T., Swennen, R., and De Waele, D. 1999. Effect of time and inoculum density on the reproductive fitness of Pratylenchus coffeae and Radopholus similis populations on carrot disks. Nematology 1:243-250.
Townshend, J. L. 1974. Monoxenic culture of Paratylenchus projectus. Nematologica 20:264-266.

Troccoli, A., Vovlas, N., and Inserra, R. N. 2002. Parasitism of timber bamboo roots by Gracilacus latescens raski, 1976 and morpho-biological notes on mature and immature life stages. Nematropica 32:87-102.

Uchida, J. Y., Sipes, B. S., and Kadooka, C. Y. 2003. Burrowing nematode on anthurium: Recognizing symptoms, understanding the pathogen, and preventing disease. Univ. Hawaii CTAHR Plant Dis. Publ. PD-24.

Wang, K., Xie, H., Li, Y., Xu, C. L., Yu, L., and Wang, D. W. 2013. Paratylenchus shenzhenensis $\mathrm{n}$. sp. (Nematoda: Paratylenchinae) from the rhizosphere soil of Anthurium andraeanum in China. Zootaxa 3750:167-175.

Wang, S. J., Duan, Y. X., Jin, Y. Y., and Chen, L. J. 2008. Artificial rearing of the rice white-tip nematode (Aphelenchoides besseyi). Plant Prot. 34:46-48.

Zhang, C., Xie, H., Xu, C. L., Cheng, X., Li, K. M., and Li, Y. 2012. Differential expression of Rs-eng- $1 b$ in two populations of Radopholus similis (Tylenchida: Pratylecnchidae) and its relationship to pathogenicity. Eur. J. Plant Pathol. 133 899-910.

Zhu, L. H., Ye, J., Negi, S., Xu, X. L., Wang, Z. L., and Ji, J. Y. 2012 Pathogenicity of aseptic Bursaphelenchus xylophilus. PLoS One 7:e38095. 